\title{
QUASE MINISTRO: ERA UMA VEZ UM CAVALO
}

\section{NILTON DE PAIVA PINTO}

Universidade Federal de Minas Gerais

Belo Horizonte, Minas Gerais, Brasil

Resumo: Este artigo analisa a comédia Quase ministro, de Machado de Assis, escrita e representada em 1863. Na peça, diversos tipos de aduladores rodeiam o deputado que aguarda sua nomeação para o ministério. A relação entre os personagens e os costumes políticos no Brasil daquele período conferem à comédia o caráter de sátira política.

Palavras-chave: Literatura brasileira; Teatro brasileiro; Machado de Assis.

\section{QUASE MINISTRO: ONCE UPON A TIME A HORSE}

Abstract: This paper analyzes Machado de Assis's comedy Quase ministro, written and performed in 1863. In the play, various types of flatterers surround the deputy who awaits his appointment to the ministry. The relationship between the characters and the political customs in Brazil at that time gave the comedy the character of political satire.

Keywords: Brazilian Literature; Brazilian Theater; Machado de Assis.

comédia Quase ministro, de Machado de Assis, foi redigida em 1863, para ser representada num dos saraus literários e artísticos que se realizavam na casa da rua do Quitanda, n. 6, residência dos irmãos Joaquim e Manuel de Melo, amigos do autor. A peça foi representada em 22 de novembro daquele ano. Todos os seus personagens são do sexo masculino, porque não era permitida a presença de pessoas do sexo feminino naquelas reuniões. ${ }^{1}$

\footnotetext{
${ }^{1}$ Cf. MACHADO, 2008, p. 280; SOUSA, 1955, p. 377-379.
} 
A peça tem um ato, e catorze cenas; ${ }^{2}$ a ação se passa na cidade do Rio de Janeiro, enquanto corre pela cidade o boato de que o deputado Martins será nomeado ministro. Na cena I, Silveira e Martins encontram-se na elegante sala da casa do deputado. Silveira é primo de Martins, e sua chegada à residência dá oportunidade à apresentação da situação inicial, e, ao mesmo tempo, anuncia figuradamente o desfecho da comédia. O político cotado para o ministério está em sua intimidade, em diálogo com o primo, que lhe narra uma queda de cavalo que acabara de sofrer. Silveira não deixa de pedir ao parente algum benefício, no caso de ele vir a ser ministro - pedido a que Martins responde com a jocosidade própria de conversa entre familiares: "Quando houver a pasta dos alazões...".

O diálogo entre os dois mistura dois assuntos: a queda que Silveira acabara de sofrer de seu alazão e a iminência da nomeação de Martins para o ministério. Silveira chega esbaforido, dizendo-se ressuscitado depois da queda. A partir da referência à queda como um “desastre”, é introduzido o segundo assunto:

\section{MARTINS}

Acabaste a história do teu desastre?

SILVEIRA

Acabei.

MARTINS

Ouve agora o meu.

SILVEIRA

Estás ministro, aposto!

MARTINS

Quase.

SILVEIRA

Conta-me isto. Eu já tinha ouvido falar na queda do ministério.

MARTINS

Faleceu hoje de manhã.

SILVEIRA

Deus lhe fale n'alma!

\footnotetext{
${ }^{2}$ A mudança de cena é marcada pela entrada ou saída de personagens.

${ }^{3}$ ASSIS, 2003, p. 242. Deste ponto em diante, as citações da peça serão indicadas apenas pelas páginas nessa edição, no corpo do texto.
} 


\section{MARTINS}

Pois creio que vou ser convidado para uma das pastas.

SILVEIRA

Ainda não fostes?

\section{MARTINS}

Ainda não; mas a notícia já é tão sabida na cidade, ouvi isto em tantas partes, que julguei dever voltar para casa à espera do que vier. (p. 241242)

Está criada a circunstância propícia ao assédio de pretendentes a graças e benefícios. As palavras, nessa cena, são utilizadas em seu sentido próprio, no registro denotativo. Vê-se, entretanto, na passagem citada, um exemplo de prosopopeia: à queda do ministério Martins aplica a expressão - "Faleceu hoje de manhã" -, como se fora o ministério um ser vivo. Há, ainda, outra prosopopeia, ao final da cena. Quando batem palmas à porta (é o primeiro pretendente, cuja entrada faz a peça passar à cena II), Silveira pergunta: “Será a pasta?" (p. 242) Ocorre, no caso, a personificação da esperada notícia da elevação de Martins à condição de ministro. Era tão forte a convicção da nomeação, que a chegada da notícia é tratada de modo concreto, como a chegada de uma pessoa a casa. A linguagem não está empregada de forma direta, referencial - porque a notícia não é uma pessoa; o deslizamento de sentido tem efeito humorístico.

O primeiro assunto tratado na cena I é a queda de Silveira, que ocorrera em Botafogo. $\mathrm{O}$ acontecimento narrado por ele, a queda do cavalo, prefigura o destino da expectativa de Martins em relação à sua indicação para o ministério, da expectativa do próprio Silveira, que pretendia tirar algum proveito da situação do primo, das expectativas de todos os velhacos que assediam o suposto futuro ministro; todos irão cair do cavalo, ou seja, serão todos surpreendidos com a notícia desagradável da não nomeação.

Neste caso, o que temos é um acontecimento prefigurando outro acontecimento, o que é uma "interpretação figural" - tipo de interpretação em que "um acontecimento terreno é elucidado pelo outro; o primeiro [a queda do alazão] significa o segundo [o fato de todos caírem do cavalo, isto é, não terem suas expectativas realizadas], o segundo 'realiza' o primeiro.” (CARONE, 1997, p. 9). Na economia dramática da comédia, nada se desperdiça; a aparentemente simples queda do cavalo sofrida por Silveira não está onde está por acaso - ela significa, ela anuncia, ela prefigura, ela faz sentido. 
No final da comédia, na cena XIII (penúltima), todos os personagens estão presentes em cena. Com a decepção, eles saem um a um, restando na sala apenas os dois que estavam no início da comédia - Martins e Silveira -; eles conversam sobre a situação de terem sido abandonados pelos bajuladores. A peça se encerra na cena XIV, com a retomada do primeiro acontecimento, a queda do alazão:

\section{Cena XIV}

MARTINS e SILVEIRA

MARTINS

Que me dizes a isto?

\section{SILVEIRA}

Que hei de dizer! Estavas a surgir... dobraram o joelho: repararam que era uma aurora boreal, voltaram as costas e lá se vão em busca do sol... São especuladores!

\section{MARTINS}

Deus te livre destes e de outros...

SILVEIRA

Ah! livra... livra. Afora os incidentes como o [de] Botafogo... ainda não me arrependi das minhas loucuras, como tu lhes chamas. Um alazão não leva ao poder, mas também não leva à desilusão.

\section{MARTINS}

Vamos jantar. (p. 278-279)

Silveira emprega metáforas para referir-se à situação de Martins: "estavas a surgir", "era uma aurora boreal”, "lá se vão em busca do sol”. A "aurora boreal” equivale ao fracasso de Martins, que não se elevará ao cargo de ministro; os bajuladores lhe dão as costas e vão atrás do novo indicado ao ministério, para apresentar-lhe (como apresentaram a Martins) suas pretensões - "em busca do sol”.

Silveira encaminha o diálogo para a conclusão, formulando um provérbio: "Um alazão não leva ao poder, mas também não leva à desilusão." Martins estava desiludido, prefere esquecer o assunto, e chama o primo para jantar. Termina assim a peça. 
Vimos que Martins decidiu ficar em casa, aguardando a notícia de que fora elevado a ministro. Enquanto espera, começa o assédio dos pretendentes. O primeiro aparece na cena II, é José Pacheco, que se apresenta como publicista - ele assina seus artigos como "Armand Carrel”. Esse pseudônimo revela muito sobre as pretensões do articulista. Armand Carrel (1800-1836) foi um jornalista e ensaísta francês, que fundou, com Thiers e Mignet, o jornal Le National. Adolphe Thiers (1797-1877), companheiro de Carrel, além de jornalista e historiador, foi político importante, que chegou a ser presidente da República em $1871{ }^{4}$

Há uma ligação indireta entre Armand Carrel e Machado de Assis. Carrel morreu em virtude de ferimentos provocados por um duelo com Émile de Girardin (1806-1881). ${ }^{5}$ Este, por sua vez, escreveu, em parceria com Alexandre Dumas Filho, Le supplice d'une femme (1865) - peça traduzida por Machado de Assis com o título de "Suplício de uma mulher" (1865) (MACHADO, 2008, p. 148).

O Armand Carrel brasileiro se insinua como uma espécie de assessor político ao quase ministro Martins, sendo caracterizado como parasita por Silveira (cena III). A figura do parasita havia sido objeto de considerações, por Machado de Assis, na série de textos intitulada "Aquarelas", publicada em $O$ Espelho em 1859 (ASSIS, 2008b, v. 3, p. 996-1007). Afirma ele: "O mais vulgar e o mais conhecido é o [parasita] da mesa; mas há-os também em literatura, em política e na Igreja.” (ASSIS, 2008b, v. 3, p. 998). Pacheco, ao final da cena II, escapando-se do convite de Silveira para ir ver os cavalos novos que pretendia comprar, retira-se, prometendo voltar para o jantar. Portanto, ele é um parasita da mesa; mas não é só isso - ele é, também, um parasita em política. Ele procura galgar as escadas do poder. Veja-se sua técnica:

\section{PACHECO}

É o que lhe digo. Depois dos meus artigos, principalmente o V, não é lícito a ninguém recusar uma pasta, só se absolutamente não quiser servir o país. Mas nos meus artigos está tudo, é uma espécie de compêndio. Demais, a situação é nossa; nossa, repito, porque eu sou do partido de V. Exa.

\footnotetext{
${ }^{4}$ Cf. NOUVEAU, t. I, p. 297, e t. II, p. 920; ENCICLOPÉDIA, v. IV, p. 2216.

${ }^{5}$ Cf. NOUVEAU, t. I, p. 297; ENCICLOPÉDIA, v. IV, p. 2216.
} 
MARTINS
É muita honra.

PACHECO

Uma vez que se compenetre da situação está tudo feito. Ora diga-me, que política pretende seguir?

\section{MARTINS}

A do nosso partido.

\section{PACHECO}

É muito vago isso. O que eu pergunto é se pretende governar com energia ou com moderação. Tudo depende do modo. A situação exige um, mas o outro também pode servir... (p. 245-246)

Como parasita em política, ele é bem característico. Explica Machado de Assis que o parasita age "tomando uma opinião ao grado das circunstâncias, deixando-a ao paladar das situações" (ASSIS, 2008b, v. 3, p. 1003). Não é senão isso o que faz Pacheco, quando diz que tanto a energia como a moderação são defensáveis - o que ele insinua com as reticências. Ele se comporta como um "parasita do espírito e da consciência": "Não podendo imitar os grandes homens pelo talento, copia na postura e nas maneiras o que acha pelas gravuras e fotografias." (ASSIS, 2008b, v. 3, p. 1002) ${ }^{6}$ Assinar seus artigos com o nome de Armand Carrel é o mesmo que copiar posturas e maneiras de um célebre publicista - é o meio de que ele lança mão para ocultar sua inópia mental. ${ }^{7} \mathrm{O}$ espartilho da vaidade, outra característica dos parasitas “do espírito e da consciência”, fica representado no ar pedantesco de Pacheco, é posto em evidência na sua insistência sobre a enumeração de seus artigos e sobre sua erudição - "há de lembrar-se de um deles, creio que é o IV, não, é o V" (p. 244); "Depois dos meus artigos, principalmente o V, não é lícito a ninguém recusar uma pasta" (p. 245); "Cito aí boa soma de autores. Eu, de ordinário, cito muitos autores.” (p. 248)

Para completar seu perfil de parasita - "certa erva que desdenha a terra para enroscar-se, identificar-se com as altas árvores” (ASSIS, 2008b, v. 3, p. 998) -, Pacheco diz, também, o seguinte: "Sou capaz de impugnar hoje os atos de um ministro e ir amanhã almoçar com ele.” (p. 247)

\footnotetext{
${ }^{6}$ Passamos os verbos para o singular, para adaptar a frase genérica a este personagem em particular.

7 “inópia mental" é a expressão que Machado de Assis utilizou em "Teoria do medalhão", para caracterizar o personagem Janjão. Em "O parasita”, já se encontra a semente da "Teoria do medalhão". Na peça de teatro, a teoria é posta em ação, diante do espectador. Cf. ASSIS, 2008b, v. 2, p. 263.
} 
Esta cena II diferencia-se das cenas inicial e final, em que Martins conversa com Silveira, pela ausência de linguagem figurada e da dimensão poética da linguagem - o que combina muito bem com a figura prosaica do parasita.

É graças aos cavalos de Silveira que Martins consegue livrar-se de Pacheco, que vai embora quando o primeiro o convida para ver os cavalos que vai comprar: "Se não lhe falas em cavalos ainda aqui estava!" (p. 252) diz Martins ao primo, na cena III, depois da saída de Pacheco. Isso resultará em humor na cena seguinte (IV). Imediatamente depois da saída do primeiro pretendente, alguém anuncia com palmas que está chegando - é Carlos Bastos, que se apresenta como poeta: "Sou filho das musas." (p. 253) Apavorado diante da perspectiva de ter de aturar mais um maçante, Martins troca com Silveira as seguintes palavras, quando este anuncia que vai sair da sala (depois que Bastos já se sentou):

\section{SILVEIRA}

Bem, com licença.

\section{MARTINS}

Onde vais?

\section{SILVEIRA}

Vou lá dentro falar à prima.

\section{MARTINS}

(baixo)

Presta-me o auxílio dos teus cavalos.

\section{SILVEIRA}

(baixo)

Não é possível, este conhece o Pégaso. Com licença. (p. 253)

A linguagem indireta, aí, é manifesta. É esta a segunda ocasião em que Silveira, por associação com seus cavalos, menciona o mundo antigo. Na cena I, ele associara os cavalos a Calígula; nesta, ele lança mão da figura do cavalo alado da mitologia grega - Pégaso -, para dizer que falar de cavalos com o poeta que se referira às musas seria o mesmo que provocar uma avalanche de palavras sobre o mundo clássico. Ou seja, seria dar assunto ao importuno da vez. Com isso, Silveira sai da sala, e começa a cena V, em que dialogam Martins e Carlos Bastos. 
Não foi necessária a referência a cavalos para despertar no poeta Carlos Bastos a enxurrada de referências clássicas. Para início de conversa, ele se apresenta como "filho das musas" (p. 254); na sequência busca uma maneira de relacionar poesia e política: "A poesia e a política acham-se ligadas por um laço estreitíssimo. O que é a política? Eu a comparo a Minerva. Ora, Minerva é filha de Júpiter, como Apolo. Ficam sendo, portanto, irmãs.” (p. 255) Apolo era o Sol, na mitologia grega; comandava as musas e era o protetor das artes; deus da harmonia, da música e da inspiração poética. Minerva, deusa romana, é identificada com a deusa grega Atena, que é filha de Zeus (Júpiter, em Roma), de cuja cabeça saiu, inteiramente armada; era deusa da razão e da sabedoria (GRANDE, v. 1, p. 200 e p. 271).

Bastos se vale do parentesco dos deuses para justificar o ímpeto poético que recebeu de sua musa quando soube da futura nomeação de Martins para o ministério: "Introduziu-me [a musa] na cabeça a faísca divina, emprestoume as suas asas, e arrojou-me até onde se arrojava Píndaro.” (p. 255) Este foi um dos mais importantes poetas gregos, cuja poesia se caracterizava pela audácia dos pensamentos e das metáforas, pela harmonia, pelo brilho e pela majestade do estilo e pela energia da expressão (GRAVE, COELHO NETO, s.d., v. III, p. 668). As odes de Píndaro exaltam os vencedores na guerra e nos jogos olímpicos, assim como os povos e cidades cuja magnitude se reflete na glória dos heróis. Trata-se de um lirismo de expressão coletiva, ligado à vida pública. Esses são os argumentos que Bastos utiliza para explicar a composição de uma ode dedicada a Martins: "tenho sido cantor de todos os ministérios” (p. 257) - diz ele.

O que ele diz é uma confissão de que frequenta a casa de cada ministro que sobe; com isso, Bastos deixa claro que também pertence à categoria dos parasitas, o que se reforça quando, depois de Martins recusar-se a ouvir-lhe a ode, propõe-se a lê-la ao jantar diante dos amigos do suposto recémnomeado ministro: "então, no melhor da festa, entre a pera e o queijo, levanto-me eu, como Horácio à mesa de Augusto, e desfio a minha ode!” (p. 256)

Martins tenta, de todos os modos, livrar-se de Carlos Bastos, que insiste em permanecer em sua companhia, com a desculpa de querer ser dos primeiros a abraçá-lo quando vier a confirmação da notícia de sua escolha para o ministério. A essa altura, chega Mateus (e começa a cena VI), o que dá motivo para que Martins faça Bastos ir embora - então, começa a cena VII, com apenas Martins e Mateus em cena.

O novo adulador apresenta ao futuro ministro sua pretensão: ele pede privilégio para seu invento - privilégio que vinha sendo negado pelos 
ministérios anteriores. Diz ele: "Inventei uma peça de artilharia; coisa inteiramente nova; deixa atrás de si tudo o que até hoje tem sido descoberto. É um invento que põe na mão do país, que o possuir, a soberania do mundo.” (p. 261) A essa invenção, para dar ideia de seu poderio, ele pretende denominar "O raio de Júpiter" (p. 261). Mais uma referência ao mundo clássico.

A ausência de linguagem figurada, nesta cena (VII), dá destaque à referência clássica. Essa característica combina com as ambições prosaicas de Mateus. Martins, enfadado com o assédio - este já é o terceiro bajulador que aparece em sua casa -, aproveita a entrada de Silveira (cena VIII) e abandona a sala - o que dá ensejo ao início da cena IX, em que dialogam Mateus e Silveira. Aquele diz a este, sobre seu maquinismo:

[...] não é o primeiro; tenho inventado outras coisas. Houve um tempo em que me zanguei; ninguém fazia caso de mim; recolhi-me ao silêncio, disposto a não inventar mais nada. Finalmente, a vocação sempre vence; comecei de novo a inventar; mas nada fiz ainda que chegasse à minha peça. Hei de dar nome ao século XIX. (p. 265)

Como se vê, Mateus é um ressentido; compensa isso com a megalomania: pretende-se inventor do "raio de Júpiter" e aspira à fama, deseja a "dar nome ao século XIX". Ele representa bem os bajuladores que costumam circular no entorno dos poderosos.

A partir da cena $X$, começa o processo de reunião de todos os personagens na sala, processo que culmina na cena XIII (penúltima). Conversam Mateus e Silveira quando aparece Luís Pereira (e tem início a cena $\mathrm{X}$ ), bajulador que vem oferecer um jantar ao futuro ministro e, ao mesmo tempo, convidá-lo para batizar um de seus filhos.

Pereira explica: "E há uma coisa singular: conto os meus filhos por ministérios. Casei-me em 50; daí para cá, tantos ministérios, tantos filhos.” (p. 267) A duração média de cada gabinete era de pouco mais de um ano - o que significa um filho por ano. Luís Pereira, portanto, contraria a representação da família na ficção machadiana. Lúcia Miguel Pereira observa a falha de Machado de Assis na reconstituição de sua época, no tocante à estrutura das famílias - em sua obra, "quase só existem famílias pequenas”. É nisso que reside a falha do autor na representação da realidade 
social brasileira daquele tempo. Luís Pereira oferece, no conjunto da obra machadiana, um contraponto; esse aspecto da realidade não escapou de todo ao autor. O casamento de Luís Pereira representa muito bem o seu tempo; tinha um filho por ano, como era característico da época, em que as famílias pululavam de crianças, e as mulheres "muitas vezes literalmente se esvaíam na procriação, pois se não morriam de parto cedo envelheciam, perdiam com as maternidades repetidas as graças femininas" (PEREIRA, 1958, p. 19).

Com a fala breve de Luís Pereira sobre sua família, Machado de Assis, com uma pincelada rápida, aponta para todo um extenso território social sem que ele seja examinado em seus detalhes.

Da intimidade da família brasileira salta-se, com a entrada de Agapito e Müller, à presença de um estrangeiro na capital do Império (cena XI). Com estes, são cinco os personagens em cena. No diálogo que acontece em seguida, entram em pauta questões relevantes para a compreensão da estrutura social e política daquele tempo.

Em primeiro lugar, Müller é um estrangeiro, de Hanover, que entra acompanhado por Agapito, que é brasileiro e se encarrega de apresentá-lo a pessoas que possam atender aos interesses dele. Em segundo lugar, aparece o conflito entre o nacional e o estrangeiro: Müller se propõe a trazer ao Brasil “os melhores artistas da época” (p. 269), no que é contestado por Mateus, que defende “os talentos do país” (p. 270). Na verdade, Mateus está defendendo seus próprios interesses, pois ele competia também por um patrocínio para sua invenção, que era nacional e poderia pôr "na mão da pátria a soberania do mundo". (p. 270) Contra o argumento da "soberania do mundo" pelas armas, Agapito defende a soberania pela música, "que vence a ferocidade" citando Orfeu na passagem (outra referência clássica).

Machado de Assis não via com muito bons olhos a importação de teatro; para ele, a figura do tradutor dramático é uma "espécie de criado de servir que passa de uma sala a outra os pratos de uma cozinha estranha”; o teatro importado "não tem cunho local; reflete a sociedade estranha, vai ao impulso de revoluções alheias à sociedade que representa” (ASSIS, 2008a, p. 136 e p. 135, respectivamente). Assim, o personagem estrangeiro representa uma ideia de que Machado de Assis discorda. Segundo ele:

Para que a literatura e a arte dramática possam renovar-se, com garantias de futuro, torna-se indispensável a criação de um teatro normal. Qualquer paliativo, neste caso, não adianta coisa nenhuma, antes atrasa, pois que é necessário ainda muito tempo para colocar a arte dramática nos seus verdadeiros eixos. A iniciativa desta medida só pode partir dos poderes do Estado; o Estado que sustenta uma academia 
de pintura, arquitetura e estatuária, não achará razão plausível para eximir-se de criar uma academia dramática, uma cena-escola, onde as musas achem terreno digno delas, e que possa servir para a reforma necessária no gosto público (ASSIS, 2008a, p. 398).

No debate que ocorre na peça, diante da opinião de Silveira de que o primo (futuro ministro) não aceitará a proposta (de Müller), emerge a questão da promiscuidade das relações entre a esfera dos negócios públicos e a dos interesses privados: Agapito deseja o sucesso do empreendimento de Müller para que ele próprio possa namorar a prima-dona. Conforme Richard Graham, no Brasil do século XIX (segundo reinado), não havia oposição efetiva entre o poder público e o poder privado: "Eu também vejo os ricos usando uma estrutura de governo que eles próprios criaram para promover seus interesses.” (GRAHAM, 1997, p. 19) - diz ele.

Agapito alega que votou com Martins nas eleições e invoca, em seu interesse, o sistema de sustentação recíproca entre as classes, marcado pelo favor (SCHWARZ, 1988, p. 16).

Na sequência, nesta galeria de tipos, retornam à casa de Martins os personagens Pacheco e Carlos Bastos, que já tinham passado por lá. Com isso são sete em cena. Os dois que chegam são aparentados pela atividade “intelectual” que exercem: Bastos é poeta e Pacheco é publicista. O diálogo da cena envolve apenas os dois personagens que acabam de chegar; Silveira tem três falas breves - em duas faz as vezes de anfitrião (Martins está ausente), numa ele manifesta concordância com os elogios que Pacheco faz ao futuro ministro. No mais, Pacheco e Carlos Bastos emitem suas opiniões, exibindo-se com erudição: Bastos mencionando diversas referências clássicas; Pacheco, não querendo ficar-lhe atrás, acaba fazendo também uma.

Pacheco defende que a política a ser adotada pelo novo gabinete deve ser a moderada. Bastos, expandindo-se num arroubo discursivo, faz um contraponto ao outro, e, para isso, lança mão de referências clássicas (heroicas): "[...] o que sei é que S. Exa. deve colocar-se na altura que lhe compete, a altura de um Hércules. O déficit é o leão de Nemeia; é preciso matá-lo.” (p. 274)

Dos doze trabalhos de Hércules, impostos a ele por Eristeu, o primeiro foi o enfrentamento do Leão de Nemeia, considerado invulnerável, mas que foi por ele asfixiado com a força de seus braços. O leão devorava os habitantes e os rebanhos da região (Nemeia) (KURY, 1999, p. 182). Carlos Bastos, em sua linguagem de poeta, faz a equivalência entre o "déficit”, praga 
das finanças públicas em todos os tempos, e o leão de Nemeia, flagelo daquele lugar (GRANDE, 1988, v. 6, p. 2310).

Contra a política da moderação proposta por Pacheco, Carlos Bastos invoca ainda outros heróis gregos: "Mas que moderação é essa? [...] Recorramos aos heróis... Aquiles foi moderado? Heitor foi moderado? Eu falo pela poesia, irmã carnal da política, porque ambas são filhas de Júpiter.” (p. 274) Moderação é tudo o que não havia em Aquiles - basta lembrar as palavras iniciais da Ilíada, tantas vezes parodiadas por Machado de Assis: "Canta, ó Musa, a ira de Aquiles, filho de Peleu, que incontáveis males trouxe às hostes dos aqueus." (HOMERO, s.d., p. 11). Heitor, filho de Príamo, rei de Troia, matou Pátroclo e, por isso, foi morto por Aquiles, tomado de furor pela morte do amigo. No episódio em questão, Heitor comportou-se com imoderação, não atendendo aos apelos de seu pai (Príamo) e sua mãe (Hécuba) para retornar à cidade, onde já se tinham abrigado os demais troianos (KURY, 1999, p. 174-175).

O fato de poesia (Apolo) e política (Minerva) serem ambos filhos de Júpiter, resulta na seguinte fala de Pacheco: "Eu já disse que sou da política de S. Exa.; e contudo ainda não sei (para falar sempre em Júpiter...) ainda não sei se ele é filho de Júpiter Libertador ou Júpiter Estator [...].” (p. 275) Com essas referências, pretendia Pacheco fazer a oposição entre governar com energia ou com moderação. "Stator" era um dos sobrenomes de Júpiter (SARAIVA, s.d., p. 1125), associado a momentos em que fez parar inimigos de Roma: caso dos sabinos, quando atacaram a cidade, e dos samnitas, que a atacaram em três guerras. "Libertador" é outro epíteto de Júpiter, cultuado em Roma no Templo da Liberdade. ${ }^{8}$

A partir da cena seguinte (XIII), o número de personagens simultaneamente no palco chega a oito, com o retorno de Martins. O esperado futuro ministro chega com a notícia fatal: "o boato que correu hoje desde manhã é falso... O ministério está completo, sem mim.” (p. 276) À notícia, todos reagem com um sonoro "Ah!" - o que rompe com a expectativa de todos e, consequentemente, pela simultaneidade das reações, é fonte de humor e provoca riso. O conjunto dos pretendentes reage da mesma forma, com a mesma exclamação, e ao mesmo tempo: parecem regidos por um

\footnotetext{
8 Cf. GRANDE, v. 7, p. 2868 e p. 2891; ver também os sites: https://pt.wikipedia.org/wiki/Templo_de_Júpiter_Estator_(século_VIII_a.C.); SARAIVA, Novíssimo dicionário latino-português, p. 676; https://pt.wikipedia.org/wiki/Templo_da_Liberdade.
} 
mecanismo. Sobre a reação humana lembrar algo mecânico, diz Henri Bergson: "Atitudes, gestos e movimentos do corpo humano são risíveis na exata medida em que esse corpo nos leva a pensar num simples mecanismo." (BERGSON, 1983, p. 23). Há um quê de mecânico nessa simultaneidade e na identidade das reações; apesar de inesperada, a notícia provoca a mesma atitude em todos os personagens, como se eles estivessem programados para agir daquele modo.

Todos se preparam para sair, em busca do novo ministro, para apresentar-lhe suas demandas. Toda a ação irá se repetir perante o novo indicado para o ministério. Também na ação prefigurada há um quê de repetição mecânica.

Diante da atitude dos bajuladores, Silveira, ironicamente, tenta retê-los em casa de Martins, com a seguinte alegoria:

Ouçam ao menos uma história. É pequena, mas conceituosa. Um dia anunciou-se um suplício. Toda gente correu a ver o espetáculo feroz. Ninguém ficou em casa: velhos, moços, homens, mulheres, crianças, tudo invadiu a praça destinada à execução. Mas, porque viesse o perdão à última hora, o espetáculo não se deu e a forca ficou vazia. Mais ainda: o enforcado, isto é, o condenado, foi em pessoa à praça pública dizer que estava salvo e confundir com o povo as lágrimas de satisfação. Houve um rumor geral, depois de um grito, mais dez, mais cem, mais mil romperam de todos os ângulos da praça, e uma chuva de pedras deu ao condenado a morte de que o salvara a real clemência. - Por favor, misericórdia para este (apontando para Martins). Não tem culpa nem da condenação, nem da absolvição. (p. 277-278)

O suplício do condenado equivale à nomeação de Martins, que se veria às voltas com os encargos de ministro. Como na história toda a gente vai à praça assistir ao suplício, os bajuladores se apresentam em casa de Martins; sua não nomeação equivale à absolvição do condenado, pela clemência real. A partir desse ponto, o que sucede em cena (o afastamento dos pretendentes) parece ser o contrário do que sucede na praça (o movimento em direção ao condenado absolvido, e seu apedrejamento); no entanto, o resultado é o mesmo - o condenado, salvo pela clemência real, é apedrejado, ao passo que Martins, salvo do suplicio pela não nomeação, tem negado o pedido de misericórdia feito por Silveira, ele é abandonado. À morte por apedrejamento equivale o abandono - mortes diferentes, uma no plano físico (a do condenado absolvido), a outra no plano moral (a do deputado Martins). 
Depois da história, todos os seis personagens partem, deixando em cena apenas Martins e Silveira (cena XIV). Essa última cena se articula com a primeira, conforme foi visto. E Martins entra na galeria dos personagens machadianos assim caracterizados por Raimundo Faoro: “A desilusão [dos personagens machadianos ambiciosos] é especificamente política: o ministério está fora do alcance dos políticos da obra de ficção de Machado de Assis [...].” (FAORO, 1976, p. 113) No teatro machadiano, que também é ficção, o ministério está fora do alcance dos políticos.

Conforme vimos, a comédia Quase ministro apresenta uma parte central, e uma moldura constituída pelas cenas inicial e final. No miolo da peça, desfilam tipos da sociedade carioca, todos eles objeto da sátira levada a efeito na comédia. Esta, evidentemente, guarda íntimas relações com a estrutura da sociedade escravagista brasileira, em que mesmo os "homens livres" eram dependentes da classe senhorial (SCHWARZ, 1988, p. 16). Pertenciam à categoria dos "homens livres" os tipos que aparecem na casa de Martins, em busca de favores. As cenas de Quase ministro representam relações necessárias na estrutura da sociedade brasileira daquele tempo.

Martins é um deputado que se encontra na perspectiva de ter acesso ao cargo de ministro. Ele encontra-se, assim, entre a esfera superior do mundo político e a sociedade.

Durante o segundo reinado, sob d. Pedro II, em 49 anos, houve 35 gabinetes (GALVÃO, 1969, p. 31-55). Quedas de ministérios, portanto, eram eventos comuns na vida política daquele tempo. Todo o interesse da comédia recai sobre o mecanismo da substituição que está para acontecer (a troca de ministros) e as consequências dessa substituição na miudeza das vidas de indivíduos livres, que buscam favores.

É esta a situação que foi posta a nu - estilizada, embora - por Machado de Assis nesta peça. José Paulo Paes empregou a expressão "ciranda”, para referir-se às trocas frequentes de ministério pelo Imperador: "a ciranda monótona de gabinetes conservadores ou liberais, liberais ou conservadores, em que se resume a história parlamentar" (PAES, 2008, p. 145) daquela época.

É tão intensa a relação entre a situação dramática e a realidade, que Quase ministro poderia muito bem ser considerada uma sátira de costumes costumes políticos, no caso. A decepção de Martins por não ter sido escolhido para o ministério, assim como as decepções de todos os parasitas 
que já o rodeavam em busca de prestígio e patrocínio, equivale moralmente à queda de um alazão. É a moral da peça - a que o adágio formulado por Silveira dá uma forma verbal: "Um alazão não leva ao poder, mas também não leva à desilusão.” (p. 279)

\section{Referências}

ASSIS, Machado de. Teatro de Machado de Assis. Edição preparada por João Roberto Faria. São Paulo: Martins Fontes, 2003.

Machado de Assis: do teatro. Textos críticos e escritos diversos. Org. João Roberto Faria. São Paulo: Perspectiva, 2008a.

Obra completa em quatro volumes. Rio de Janeiro: Editora Nova Aguilar, 2008b.

AUERBACH, Erich. Figura. Tradução de Duda Machado. São Paulo: Ática, 1997.

BERGSON, Henri. O riso: ensaio sobre a significação do cômico. Trad. Nathanael C. Caixeiro. 2. ed. Rio de Janeiro: Zahar, 1983.

CARONE, Modesto. Um roteiro do conceito de figura. In: AUERBACH, Erich. Figura. Tradução de Duda Machado. São Paulo: Ática, 1997, p. 7-11.

ENCICLOPÉDIA e dicionário internacional. Rio de Janeiro: W. M. Jackson, s.d. $20 \mathrm{v}$.

FAORO, Raimundo. Machado de Assis: a pirâmide e o trapézio. 2. ed. São Paulo: Nacional, 1976.

GALVÃO, Miguel Arcanjo. Relação dos cidadãos que tomaram parte no governo do Brasil no período de março de 1898 a 15 de novembro de 1889. 2. ed. Rio de Janeiro: Arquivo Nacional, 1969.

GRAHAM, Richard. Clientelismo e política no Brasil do século XIX. Rio de Janeiro: Editora UFRJ, 1997.

GRANDE enciclopédia Larousse cultural. São Paulo: Universo, 1988. 8v.

GRAVE, João; COELHO NETO. Lello universal em quatro volumes: novo dicionário enciclopédico luso-brasileiro. Porto: Lello \& Irmão, s.d. 4v.

HOMERO. A ilíada (em forma de narrativa). Tradução e adaptação de Fernando C. de Araújo Gomes. Rio de Janeiro: Ediouro, s.d.

KURY, Mário da Gama. Dicionário de mitologia grega e romana. 5. ed. Rio de Janeiro: Jorge Zahar, 1999.

MACHADO, Ubiratan. Dicionário de Machado de Assis. Rio de Janeiro: Academia Brasileira de Letras, 2008. 
NOUVEAU Larousse universel: dictionnaire encyclopédique en deux volumes. Paris: Librairie Larousse, 1953. 2 t.

PAES, José Paulo. Armazém literário: ensaios. Organização e apresentação Vilma Arêas. São Paulo: Companhia das Letras, 2008.

PEREIRA, Lúcia Miguel. Relações de família na obra de Machado de Assis. Revista do Livro, Rio de Janeiro, ano III, n. 11, p. 19-30, set. 1958.

PINTO, Nilton de Paiva. O teatro de Machado de Assis - 1860-1870: uma alternativa na dramaturgia brasileira. Belo Horizonte: Faculdade de Letras da Universidade Federal de Minas Gerais, 2020. [Tese de doutorado] SARAIVA, F. R. dos Santos. Novíssimo dicionário latino-português. Rio de Janeiro: B. L. Garnier, s.d.

SCHWARZ, Roberto. Ao vencedor as batatas. 3. ed. São Paulo: Duas Cidades, 1988.

SOUSA, José Galante de. Bibliografia de Machado de Assis. Rio de Janeiro: Instituto Nacional do Livro, 1955.

NILTON DE PAIVA PINTO é Doutor em Letras: Estudos Literários, área de concentração Literatura Brasileira pelo Programa de Pós-Graduação em Letras: Estudos Literários da Universidade Federal de Minas Gerais. Este artigo foi preparado a partir de um dos capítulos da tese de doutorado O teatro de Machado de Assis - 1860-1870: uma alternativa na dramaturgia brasileira, defendida em 2020. ORCID: https://orcid.org/00000003-2925-3426. E-mail: npaivapinto@gmail.com. 